\title{
Tema 3. Desarrollo de la sexualidad y prevención del abuso sexual infantil
}

\section{Presentación}

Si bien todos los temas aquí presentados revisten importancia, podemos expresar al docente y al padre de familia que esta temática es primordial e ineludible si queremos llegar a una mínima comprensión sobre el desarrollo sexual del niño, reconociendo la necesidad de comprender los conceptos de las diferentes fases de la sexualidad infantil, pero especialmente la importancia de proteger el cuerpo y la integridad afectiva de nuestros hijos, y de prevenir posibles abusos contra su vida y dignidad.

\section{Propósito (objetivo)}

Contrastar dos concepciones sobre la sexualidad infantil: el niño como ser sexuado y el niño como sujeto de una sexualidad protegida, la cual es la base de la vida afectiva y emocional saludable del infante. 


\section{Conceptualización general}

Critica a la idea generalizada de la inexistencia de la sexualidad en los niños:

Forma parte de la opinión popular acerca de la pulsión sexual la afirmación de que ella falta en la infancia y solo despierta en el periodo de la vida llamado pubertad. No es este un error cualquiera: tiene graves consecuencias, pues es el principal culpable de nuestra presente ignorancia acerca de las bases de la vida sexual. Un estudio a fondo de las manifestaciones sexuales de la infancia nos revelaría probablemente los rasgos esenciales de la pulsión sexual, dejaría traslucir su desarrollo y mostraría que está compuesta por diversas fuentes. (Freud, 1985, p. 61)

Sobre el periodo de latencia de la sexualidad infantil:

Los hallazgos extraordinariamente frecuentes de mociones sexuales que se creían excepciones y casos atípicos en la infancia, así como la revelación de los recuerdos infantiles de los neuróticos, hasta entonces inconscientes, permiten quizá trazar el siguiente cuadro de la conducta sexual en ese periodo: parece seguro que el neonato trae consigo gérmenes de mociones sexuales que siguen desarrollándose durante cierto lapso, pero después sufren una progresiva sofocación; esta, a su vez, puede ser quebrada por oleadas regulares de avance del desarrollo sexual o suspendida por peculiaridades individuales. Nada seguro se conoce acerca del carácter legal y la periodicidad de esta vía oscilante de desarrollo. Parece, empero, que casi siempre hacia el tercero o cuarto año de vida del niño su sexualidad se expresa en una forma asequible a la observación. (Freud, 1985, pp. 64-65)

Acerca de cómo se presentan los diques y obstáculos de la sexualidad infantil:

Durante este periodo de latencia total o meramente parcial se edifican los poderes anímicos que más tarde se presentarán como inhibiciones en el camino de la pulsión sexual y angostarán su curso a 
la manera de unos diques (el asco, el sentimiento de vergüenza, los reclamos ideales en lo estético y en lo moral). En el niño civilizado se tiene la impresión de que el establecimiento de esos diques es obra de la educación, y sin duda alguna ella contribuye en mucho.

¿Con qué medios se ejecutan estas construcciones tan importantes para la cultura personal y la normalidad posteriores del individuo? Probablemente a expensas de las mociones sexuales infantiles mismas, cuyo aflujo no ha cesado, pues, ni siquiera en este periodo de latencia, pero cuya energía - en su totalidad o en su mayor parte- es desviada del uso sexual y aplicada a otros fines. Los historiadores de la cultura parecen contestes en suponer que mediante esa desviación de las fuerzas pulsionales sexuales de sus metas, y su orientación hacia metas nuevas (un proceso que merece el nombre de sublimación), se adquieren poderosos componentes para todos los logros culturales. (Freud, 1985, p. 66)

Sobre las manifestaciones de la sexualidad infantil, Freud presenta varios fenómenos que se deben tener en cuenta como evidencia de la sexualidad del niño: el chupeteo, el autoerotismo, las zonas erógenas, las manifestaciones sexuales masturbatorias, la actividad de la zona anal y de las zonas genitales, entre otras.

Manifestaciones precisas de la pulsión sexual transformada en pulsión de saber aparecen en las conductas de los niños al espiar a otros niños y adultos, además de una serie de preguntas, que se hacen constantes, sobre sus genitales: ¿por qué las niñas no tienen pene?, ¿por qué los niños orinan sin sentarse?, ¿si las niñas no tienen pene, entonces qué tienen?, ¿me puede nacer como a él?, ¿me lo pueden cortar como a ella?

\section{Prevenir y denunciar el abuso sexual infantil}

El abuso sexual infantil es un problema que han soportado los niños y adolescentes desde siempre, pero que en la mayoría de las ocasiones es negado por las circunstancias en que se produce y las personas que pueden estar involucradas en los actos de abuso. Lo importante es 
entender que el maltrato sexual a menores es una forma de maltrato infantil y que es un delito que puede acarrear una pena de cárcel sin que se le otorguen beneficios para aminorar la pena.

Cualquier niño de cualquier edad y clase social puede ser víctima de abusos sexuales, no siempre evidentes, pues, aunque pueden tratarse de actos violentos, el agresor también se puede servir de promesas o amenazas para llevar a cabo actos que no dejan una huella visible o que no implican contacto físico. Además, el abuso sexual infantil comprende diversas formas, como la explotación sexual, el turismo sexual y la pornografía.

El abuso sexual se define como la utilización de un niño o niña con la finalidad de satisfacer o gratificar sexualmente a un adulto o grupo de adultos. Este es generalmente propiciado por una figura cercana, como el padrastro, o un cuidador, como un tío o un primo. Incluso puede llegar a ser cometido por un familiar consanguíneo, el padre, el hermano, el tío, caso en el cual se conoce como incesto. Otra forma de abuso sexual es aquel producido por un agresor desconocido por el niño o niña y que se denomina específicamente como ataque sexual.

Un tercer tipo es la explotación sexual, en la que el niño o niña es tratado como un objeto comercial. Comprende la prostitución infantil, la pedofilia, el tráfico de niños para turismo sexual y la pornografía con presencia del niño o a través de Internet. Este tipo de explotación también se puede dar dentro de la familia.

\section{Consecuencias del abuso sexual en los niños}

El papel de la familia es esencial en la recuperación física y emocional de la niña o del niño que ha sufrido de abuso sexual.

La atención que se le debe proporcionar a este niño no debe únicamente centrarse en el cuidado de sus lesiones físicas, sino que también es muy importante que se le brinde atención psicológica. El niño o la niña que sufre o sufrió algún abuso sexual padece diversas consecuencias, algunas de las cuales se describen a continuación, para que así se puedan llegar a detectar situaciones de abuso sexual. 
- Emocionales: miedo generalizado, agresividad, culpa y vergüenza, aislamiento, ansiedad, depresión, baja autoestima, rechazo del propio cuerpo. Temor a que no se le crea o a que sea culpado o castigado.

- Físicas: marcas en el cuerpo, sangrado, fluidos, pesadillas y problemas de sueño, cambios de hábitos en la alimentación, pérdida del control de esfínteres.

- En la conducta: consumo de drogas y alcohol, se fugan de la casa o del colegio, conductas autolesivas o suicidas, hiperactividad, bajo rendimiento escolar.

- Sociales: disminución del deseo de estar con otros niños, actitudes retraídas, falta de deseo de salir de la casa.

\section{Recomendaciones para prevenir el maltrato y el abuso infantil}

- Acompañar y comunicarse con el niño es fundamental: por el trabajo, el estudio y las ocupaciones diarias, los padres ya no conversan directamente con sus hijos. Llamadas, mensajes por el celular y un saludo rápido antes de dormir es lo que se hace hoy en las familias modernas. Es precisamente en los espacios de confianza, seguridad y comunicación, cuando se pasa tiempo a solas con los niños, donde puede surgir la confesión del abuso. Por eso son los adultos quienes deben fomentar en la casa una comunicación abierta y transparente con todos y cada uno de los miembros de la familia.

- Educarlo sobre las emociones y su cuerpo: desde pequeños, los niños deben aprender a conocer y manifestar sus emociones y sensaciones, como la alegría, la incomodidad, el asco, la rabia, la ira, el miedo, el enojo, el gusto y el disgusto, entre otras. De esta manera, el niño podrá expresarse claramente cuando otra persona intente tocar su cuerpo a escondidas, sin la presencia 
de otras personas; forzarlo a hacer lo que no quiere; tocar sus partes íntimas; abusar de él o atacarlo; el niño tiene derecho a contar lo que le está pasando, a ser escuchado, a manifestar de forma verbal o no verbal lo que le está sucediendo.

- Educación sexual, en casa y en la escuela: los niños deben recibir de sus profesores y padres charlas muy directas en las que se les hable y eduque sobre el cuerpo, la afectividad, la sexualidad y las relaciones sexo-genitales. Al recibir la información adecuada según su edad, los niños podrán identificar a un potencial abusador y podrán protegerse.

- Un espacio para la intimidad: cuando el niño tenga la edad suficiente para bañarse y vestirse solo, es necesario que sus padres, hermanos, abuelos, tíos, entre otros, respeten su derecho a la intimidad. Es una buena manera de hacerle entender al niño que él tiene sus propios espacios, que su cuerpo es sagrado, que es él quien decide sobre sí mismo y que nadie tiene derecho a vulnerarlo.

- Sobre las caricias: la regla general en casa es que todos los miembros de la familia tienen derecho a recibir, pero también a rechazar una caricia, beso o demostración de afecto de parte de cualquier persona. Del mismo modo es claro que los padres no deben obligar al niño a que abrace o bese a cualquier persona, pues eso es una decisión personal. Hay que enseñarle al niño a decir "no" y a respetar sus maneras de sentir y actuar.

- No guardar silencio: un padre de familia no puede guardar silencio si sospecha o conoce de un abuso de la intimidad y la sexualidad de su hijo, no puede encubrir a familiares, al esposo, padrastro, abuelo, amigo ni vecino; en tal caso estaría apoyando el crimen contra el niño y sería igualmente objeto de investigación y de las penas que el juez estime según la ley. 


\section{Acercamiento personal (reflexión)}

- ¿En alguna oportunidad ha conocido manifestaciones sexuales en algún niño? Descríbalas y explique cómo las leería desde los aportes conceptuales del psicoanálisis de Sigmund Freud.

- Después de leer el texto sobre la prevención del abuso sexual infantil explique por qué, pese a la existencia de una sexualidad y afectividad infantil, es una obligación proteger la integridad sexual de los niños y niñas.

- Si una madre en su infancia fue abusada sexualmente y guardó silencio, y en el presente se da cuenta de que uno de sus hijos está sufriendo abuso sexual, ¿qué debería hacer ella?, ¿cómo puede la escuela orientarla y apoyarla?

\section{Actividades sugeridas}

Búsquedas en Internet

Búsquedas de casos en prensa
- Explore y describa cuál es la ruta institucional más cercana y eficaz para denunciar casos de abuso sexual infantil (consulte sobre la ruta en las escuelas, en el Instituto Colombiano de Bienestar Familiar, en las comisarías de familia, entre otros).

- Investigue cuáles son las leyes y penas para quienes abusan sexualmente de los niños, niñas y adolescentes.

- En lo posible, encuentre una referencia sobre un supuesto abuso sexual infantil, que haya sido fruto de la fantasía de un niño. ¿Qué explicación puede darse sobre el hecho de que un niño construya estas narraciones?

- En casos como el anterior, ¿cómo cree usted que se puede lograr una posición responsable por parte de las mamás y papás acerca del cuidado de sus hijos y la sospecha continua sobre cualquier persona que se acerque a ellos?

- Encuentre al menos dos casos sobre abuso sexual de menores en las redes sociales, comente y proponga mecanismos de prevención para los niños, niñas y adolescentes. 
Preguntas para debates grupales
- ¿Los medios masivos de información incitan a los padres a que vistan a sus hijos como adultos, a que estos sigan patrones de conducta que promueven una sexualidad más temprana?

- ¿Qué tanto control deben tener los padres de familia sobre el uso de las redes sociales (Facebook, Instagram, YouTube, entre otras) en menores de dieciocho años?

\section{Bibliografía básica}

Alexander, P. (1992). Application of Attachment Theory to the Study of Sexual Abuse. Journal of Consulting and Clinical Psychology, 60(2), 185-195.

American Academy of Child and Adolescent Psychiatry (1997). Practice Parameters for the Forensic Evaluation of Children and Adolescents Who May Have Been Physically or Sexually Abused. Journal of the American Academy of Child and Adolescent Psychiatry, 36, 37s-56s.

American Psychological Association (1996). Violence and the Family: Report of the APA Presidential Task Force on Violence and the Family. Washington D. C.: American Psychological Association.

Arón, A. y Llanos, T. (2004). Cuidar a los que cuidan: Desgaste profesional y cuidado de los equipos que trabajan con violencia. Sistemas familiares, 20(1-2), 5-15.

Baita, S. (2007). Ventajas y desventajas del uso de protocolos en maltrato y abuso sexual infantil. Ponencia presentada en el I Congreso Internacional de Violencia, Abuso y Maltrato, Buenos Aires, Argentina.

Baita, S. (2010). Detección y abordaje del abuso sexual infantil. Curso de Formación Profesional para Trabajadores Sociales, Universidad Nacional de La Plata, Argentina.

Barudy, J. (1998). El dolor invisible de la infancia: Una lectura ecosistémica del maltrato infantil. Barcelona: Paidós.

Cantón, J. y Cortés, M. (2000). Guía para la evaluación del abuso sexual infantil. Madrid: Pirámide.

Freud, S. (1979) Un recuerdo infantil de Leonardo da Vinci. Buenos Aires: Amorrortu. 
Freud, S. (1985). Ensayos sobre sexualidad. Madrid: Sarpe.

Garbarino, J. y Eckenrode, J. (1996). Por qué las familias abusan de sus hijos. Buenos Aires: Granica.

Gardner, R. (1992). True and False Accusations of Child Sex Abuse. Creskill: Creative Therapeutics.

\section{Bibliografía complementaria}

Foucault, M. (1977). Historia de la sexualidad: La voluntad de saber. Madrid: Siglo XxI.

Hooper, C. (1994). Madres sobrevivientes al abuso sexual de sus niños. Buenos Aires: Nueva Visión.

Intebi, I. (2008). Abuso sexual infantil: En las mejores familias. Buenos Aires: Granica.

Jenny, C. (2002). Medical Issues in Child Sexual Abuse. En J. Myers et al. (eds.), The APSAC Handbook on Child Maltreatment (pp. 235-247). California: Sage.

Organización Mundial de la Salud (2014). Maltrato infantil: Nota descriptiva.$^{\circ}$ 150. Ginebra: Organización Mundial de la Salud.

Paine, M. y Hansen, D. (2002). Factors Influencing Children to Self-Disclose Sexual Abuse. Clinical Psychology Review, 22, 271-295.

Pereda, N. (2009). Consecuencias psicológicas iniciales del abuso sexual infantil. Papeles del Psicólogo, 30(2), 135-144.

Pereda, N., Guilera, G., Forns, M. y Gómez-Benito, J. (2009). The Prevalence of Child Sexual Abuse in Community and Students Samples: A Meta-Analysis. Clinical Psychology Review, 29(4), 328-338.

Perrone, R. y Nannini, M. (1997). Violencia y abusos sexuales en la familia: Un abordaje sistémico y comunicacional. Buenos Aires: Paidós.

Tarczon, C. (2012). Mothers with a History of Child Sexual Abuse: Key Issues for Child Protection Practice and Policy. Melbourne: Australian Center for the Study of Sexual Assault. 


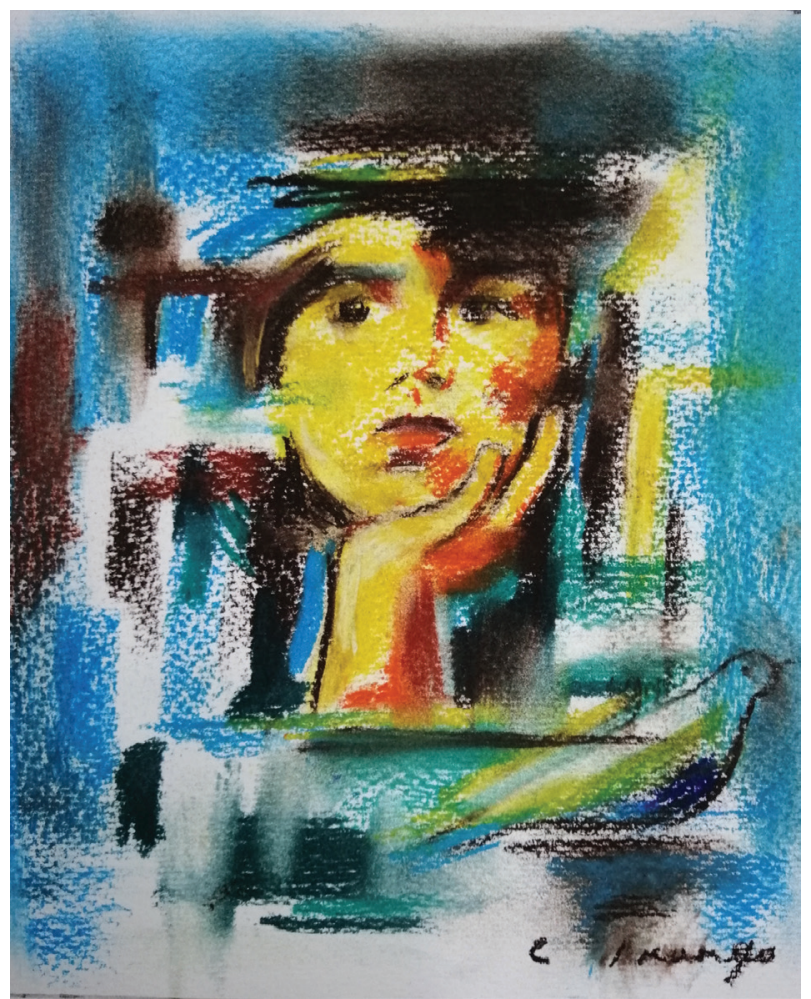

Los niños aprenden todo lo que ven en casa, en la escuela y en la calle, a veces los compañeritos que, digamos, tienen problemas en el hogar, vienen y se desquitan en el jardín, empiezan a decir palabras feas que ellos todavía no deberían saber...

Madre de familia Hogar Infantil Fundehi, barrio El Arroyo, Cazucá, Soacha, 2017 